ALISON SHAPCOTT University of the Sunshine Coast, Queensland, Australia

\section{Outbreeding ideas for conservation success}

It is increasingly recognized that interdisciplinarity is needed to tackle global challenges (Ledford, 2015, Nature, 525, 308-311), a daunting example being the problems of conserving biodiversity. However, walls between disciplines have proven no less difficult to tear down than those between nations (Reagan, 1987, Remarks at Brandenburg Gate, Berlin, Germany, 06/12/1987. www.archives.gov/historicaldocs/todays-doc/index.html?dod-date $=612$ ). Interdisciplinary research suffers consistently low funding success (Bromham et al., 2016, Nature, 534, 684-687) and there are still philistines who perceive it as the province of researchers 'who aren't good enough to make it in their own field' (Ledford, 2015, Nature, 525, 308-311).

Challenging this stubborn disciplinary cartography remains, unfortunately, the exception in applied conservation research. As an illustration, the three international conferences that the University of Oxford's Wildlife Conservation Research Unit (WildCRU) organized during the past 15 years on canid, felid and mustelid conservation hosted, despite our best efforts, only a handful of delegates (out of nearly 1,00o) with backgrounds genuinely beyond the biological sciences. Conservation scientists are sowing the seeds of inbred ideas that are decreasingly likely to germinate in today's complex world.

Emboldened by urgency and the prospect of gridlock (Hale et al., 2013, Gridlock: Why Global Cooperation is Failing when We Need It Most. Polity Press), WildCRU and the international NGO Panthera recently experimented with an alternative meeting format in an attempt to break the mould and identify innovative conservation strategies to prevent the extinction of lions Panthera leo in Africa (Bauer et al., 2015, Proceedings of the National Academy of Sciences of the United States of America, 112, 1489414899). In what we call the Oxford Format (named after its venue, in the tradition of diplomatic mechanisms; e.g. the Normandy Format to tackle the crisis in Ukraine), c. 30 lion insiders (ecologists, zoologists, geneticists from WildCRU and Panthera) brainstormed during 3 days with 30 lion outsiders (leading international political scientists, economists, philosophers, development experts) at the Cecil Summit (www.ox.ac.uk/news/science-blog/cecilsummit-another-key-milestone-lion-conservationmovement). The format began with short presentations by insiders (both researchers and those working with communities living alongside lions) on the lion's predicament, followed by short presentations by outsiders to provide radically different perspectives on this predicament. The unfolding discussions blended ideas that led to recasting lion conservation as an issue fundamentally framed by economics and governance. Paradoxically, none of these discussions focused on lion ecology but all were critically relevant to lion survival in an increasingly crowded African continent.

Although stimulating novel ideas is a far cry from implementing them, the success of the first Oxford Format summit in generating outbred ideas convinces us that the prize will be won by forcing, rather than by simply urging, interdisciplinarity to address conservation issues. There is no excuse left for inbred conservation thinking.

DAVID W. MACDONALD WildCRU, Department of Zoology, University of Oxford, The Recanati-Kaplan Centre, Tubney, Abingdon, UK

E-mail david.macdonald@zoo.ox.ac.uk

Guillaume Chapron Department of Ecology, Grimsö Wildlife Research Station, Swedish University of Agricultural Sciences, Riddarhyttan, Sweden

\section{Singapore hosts international efforts for conserving migratory waterbirds in the Asia-Pacific}

Two major international meetings targeted at the region's migratory birds have recently been hosted in Singapore, a country that has a key role in conserving waterbirds migrating from as far north as Siberia to as far south as Tasmania. What happens in the Arctic does not stay in the Arctic, and the other way around, is the mantra underpinning the conservation of Arctic breeding birds under the Conservation of Arctic Flora and Fauna working group, part of the Arctic Council, to which Singapore is an observer. This goal is being pursued through the Arctic Migratory Bird Initiative, which met on 8-9 January to discuss pressing issues in the East Asian-Australasian Flyway. Hunting of migratory waterbirds was reported from multiple countries across the flyway, raising concerns about their survival. Addressing unsustainable hunting is one of the key objectives of this Initiative, and a recommendation was made, with support from the Convention on Migratory Species, to establish a working group drawing on lessons from experience in the Mediterranean (Bird Conservation International, 2016, 26, 1-28).

The 9th Meeting of the Partners of the East AsianAustralasian Flyway Partnership took place during 11-15 January. This is a multi-actor voluntary agreement for conserving migratory waterbirds in the 22 countries of the East Asian-Australasian Flyway. The Partnership primarily focuses on habitat conservation, which remains a pressing issue, particularly in the Yellow Sea. The membership of the Partnership continues to grow, with the Hanns Seidel Foundation joining since the last Meeting. This nongovernmental organization is playing an important role through conservation and capacity building initiatives in 